Guzman, J. L., J. Caro, and B. Arroyo. 2017. Factors influencing mobility and survival of Eurasian Woodcock wintering in Spain. Avian Conservation and Ecology 12(2):21. https://doi.org/10.5751/ACE-01096-120221

Copyright (C) 2017 by the author(s). Published here under license by the Resilience Alliance.

Research Paper

\title{
Factors influencing mobility and survival of Eurasian Woodcock wintering in Spain
}

\author{
José Luis Guzmán ${ }^{1}$, Jesus Caro ${ }^{1}$ and Beatriz Arroyo ${ }^{1}$ \\ ${ }^{1}$ Instituto de Investigación en Recursos Cinegéticos (IREC, CSIC-UCLM-JCCM)
}

\begin{abstract}
Survival and mobility have important implications for population management for game species. These parameters are influenced by both intrinsic and extrinsic factors. We describe movements (commuting flights between diurnal refuges and nocturnal feeding places; and escape flights during cold spells) and winter survival rate of Eurasian Woodcock (Scolopax rusticola) wintering in Spain. We also evaluate factors influencing these variables, using 51 radio-tracked birds over three winters $(2008 / 2009,2009 / 2010$, and 2010/2011). Commuting flight distances were estimated at $961.5 \pm 1041.9 \mathrm{~m}$, and variations were mainly explained by age and temperature (they decreased with lower temperatures and were lower for first-winter birds). Three cold spells occurred in 2009/2010; 80\% of woodcocks monitored that winter showed escape flights, moving $>20 \mathrm{~km}$, and went back to their previous wintering place when the effects of cold spells finished (about 8 days later). Of monitored woodcocks, $54.9 \%$ survived the winter. The most frequent cause of death was hunting, affecting mainly first-winter birds. Woodcock survival was lower in areas with more hunting days per week, and in Mediterranean than in Atlantic climate regions. Our results highlight the importance of monitoring survival and factors affecting it. Also, these results underline the importance of developing future studies to understand the importance of Mediterranean regions, the use of refuge places during cold spells, and hunting pressure there.
\end{abstract}

\section{Facteurs agissant sur la mobilité et la survie de la Bécasse des bois hivernant en Espagne}

RÉSUMÉ. La survie et la mobilité sont des paramètres importants dans la gestion des populations pour les oiseaux gibier. Toutes deux sont influées par des facteurs tant intrinsèques qu'extrinsèques. La présente étude nous a permis de décrire les déplacements (vols quotidiens entre les refuges diurnes et les sites d'alimentation nocturne, et vols pour s'éloigner d'épisodes de froid) et la survie hivernale de la Bécasse des bois (Scolopax rusticola) hivernant en Espagne. Nous avons aussi évalué les facteurs qui agissent sur ces variables, au moyen de 51 oiseaux équipés de radio durant trois hivers (2008-2009, 2009-2010 et 2010-2011). La distance des vols quotidiens a été estimée à 961,5 \pm 1041,9 m et les variations s'expliquaient principalement par l'âge et la température (la distance diminuait quand les températures étaient plus basses et était plus courte chez les oiseaux dont c'était le premier hiver). Trois épisodes de froid sont survenus en 2009-2010; 80 \% des bécasses suivies au cours de cet hiver ont effectué des vols pour s'éloigner, se déplaçant $>20$ km et revenant au site occupé précédemment lorsque les effets du froid ont été terminés (environ 8 jours plus tard). Parmi les bécasses suivies, $54,9 \%$ d'entre elles ont survécu durant l'hiver. La cause la plus fréquente de mortalité était la chasse, laquelle touchait surtout les oiseaux dont c'était le premier hiver. La survie des bécasses était plus faible dans les endroits où le nombre de jour de chasse par semaine était plus élevé, ainsi que dans la région climatique méditerranéenne par rapport à celle de l'Atlantique. Nos résultats soulignent l'importance de surveiller la survie et les facteurs qui l'affectent. De plus, nous croyons qu'il serait opportun de faire d'autres recherches pour mesurer l'importance de la région méditerranéenne, l'utilisation de lieux refuges lors d'épisodes de froid, de même que la pression de chasse à ceux-ci.

Key Words: daily movements; escape flights; hunting management; radio-tagging; Scolopax rusticola

\section{INTRODUCTION}

Sustainable management of hunted species depends on understanding its demography, but also on knowing the appropriate spatial scale at which decisions must be made. For highly mobile species, including migratory ones, decisions taking into account only local conditions may not be appropriate or effective. For example, local movement can mask the true effect of harvest on observed densities in small areas (Williams et al. 2004). The study of mobility also provides information about ecological requirements at different times in the annual cycle (Fauchald and Tveraa 2006, Gourlay-Larour et al. 2012), and is therefore useful in terms of management for game species. For example, hunting regulations may be adjusted based on information about when certain areas are used to avoid periods or areas of population vulnerability (Péron et al. 2011a, Rodríguez-Teijeiro et al. 2012).

Mobility is known to be influenced by both intrinsic and extrinsic factors. In birds, movement decisions or distances moved have been found to differ between individuals of different age or sex (e.g., Brochet et al. 2009), and are influenced by weather, habitat fragmentation, pollution, or disturbance (Burger and Gochfeld 2004, Stephens et al. 2004, Gill 2007, Sauter et al. 2010). Understanding these relationships may also give indications 
about whether the type and extent of movements might be related to variations in fitness. For example, longer flights to obtain food may indicate ability to use space flexibly, therefore increasing the chances for individual survival (Austin et al. 2006). Conversely, because longer flights have higher energy costs, in poor food conditions they could be associated with lower survival (Wikelski et al. 2003).

The Eurasian Woodcock (Scolopax rusticola), hereafter woodcock, is a migratory wader highly reputed as a game bird in its wintering areas of Western and Southern Europe (France, the northern parts of the Iberian Peninsula, and Italy). Studies based on radio-tracking have shown that woodcock perform two types of movements during the wintering period. They make daily movements (hereafter commuting flights) at dusk and dawn between the places where they spend daytime (usually forests) and other locations at night (usually grasslands). For European wintering woodcock it has been shown that grasslands represent the main foraging areas, whereas forests represent more sheltered areas to spend the day (Cramp and Simmons 1983, Duriez et al. 2005a; although see Masse et al. 2013, where the opposite has been found for American Woodcock, Scolopax minor, in summer). Commuting flights indicate a trade-off between using good shelter and good feeding places, and the relative use of both types of places reflects the relation between energetic needs and predation risk (Duriez et al. 2004a). Additionally, when weather conditions become severe woodcock can make long-distance movements (hereafter escape flights) to more temperate places where they wait until the weather conditions change and then return to their normal wintering places (Gossmann and Ferrand 2000, Péron et al. 2011a).

Severe weather conditions in winter have in fact been found to influence woodcock survival rate (Hoodless and Coulson 1994, Tavecchia et al. 2002, Péron et al. 2011a), which decreases when earthworms become inaccessible, as happens with cold spells in winter (Péron et al. 2011a). On the other hand, survival rate in game species may be strongly influenced by hunting pressure itself, if mortality associated with hunting is additive instead of compensatory (Péron 2013). Indeed, a study in France has described spatial differences in annual survival of woodcock in relation to hunting pressure (Péron et al. 2011b, 2012), with woodcock annual survival being lower in those areas with higher hunting pressure. Considering that breeding areas and migration routes are similar for woodcock wintering in different areas in France (Bauthian et al. 2007), and therefore that any mortality effect in winter is not likely compensated by density dependent survival later in the year, this finding supports that in certain circumstances hunting pressure represents an additive source of mortality to those found at different times in the annual cycle.

Most previous studies about survival and mobility of woodcock have been developed in France, the UK, or Ireland (Wilson 1982, Hoodless and Coulson 1994, Duriez 2003), areas dominated by Atlantic climate. Knowledge about survival and movements of their wintering populations in Spain is, in contrast, scarce. The only radio-tracking study so far was carried out in the Atlanticclimate region of northern Spain (Braña et al. 2010) and there is no information about these topics in the Mediterranean-climate region. The Mediterranean-climate region is characterized by denser vegetation in the forest understory (Specht 1969). Energy expenditure by thermoregulation in dense vegetation habitats is lower than in more open ones (Wiersma and Piersma 1994), mainly because of the effect of wind (Bakken 1990). Therefore, in the Mediterranean region, thermoregulation costs (and thus energetic needs) under low temperatures may be lower on account of greater vegetation cover. Additionally, because worm availability is directly related to soil temperature (Lavelle 1988), it is also possible that the greater vegetation cover in the Mediterranean region results in that earthworm availability is less reduced under low air temperatures there.

In this paper we assess movements and survival rate of woodcock wintering in Northern Spain in sites under two climatic regions (Atlantic and Mediterranean) using radio-tracked birds, and factors influencing them. We hypothesize that commuting flight distances would be influenced by temperature, as lower temperatures increase energy needs (Duriez et al. 2004b), but that this relationship may be influenced by climatic region. Second, we hypothesize that survival rate would also be influenced by temperature, but that, as for commuting flight distances, the relationship between temperature and survival rate may be modulated by climatic region, and that survival rate would also depend on hunting opportunities, i.e., number of hunting days allowed per week in each area (Tavecchia et al. 2002). Additionally, we describe escape flights observed, conditions eliciting this behavior, and duration of the displacements. Finally, we discuss our results in relation to management of this species.

\section{METHODS}

\section{Study species}

The woodcock is a forest migratory wader with a Palearctic distribution, breeding in temperate regions of Asia and Europe (Cramp and Simmons 1983). It has a large breeding population and trends appear to be stable (BirdLife International 2016), although important declines have been observed in areas like the UK (Heward et al. 2015). Recent studies of the wintering populations of Western Europe describe a stable tendency in recent decades, although with important annual variations in abundance (Aebischer and Baines 2008, Ferrand et al. 2008, Guzmán and Arroyo 2015).

\section{Study areas and years}

We radio-tracked woodcock in winters 2008/2009, 2009/2010 and 2010/2011 in two provinces of Northern Spain (Fig. 1). In the winter of 2008/2009, monitoring took place in three valleys of Navarra province (Ulzama, Baztán, and Esteribar); in the winters of 2009/2010 and 2010/2011, it took place in two municipalities of Álava province (Kuartango and Zuia; Fig. 1). The study area was located between the sub-Atlantic and sub-Mediterranean climatic regions, with an irregular topography where the altitude varies between 300 and $600 \mathrm{~m}$, and landscape is dominated by forest-grassland mosaic. In the areas of Ulzama, Zuia, and Baztán Atlantic climate dominates, characterized by temperate weather, important rainfall throughout the year, and where predominant vegetation cover types are deciduous forest of beech, oak, and mixed formations of these (Fagus sylvatica, Quercus petraea, $Q$. robur and $Q$. pyrenaica) including patches of conifer reforestation (Pinus radiata, P. nigra and Chamaecyparis lawsoniana). In contrast, in Kuartango and Esteribar 
Mediterranean climate dominates, with warm and drier summers, and the predominant tree layer is composed of sclerophyllous forest $(Q$. ilex and $Q$. faginea) with dense Mediterranean scrub and conifer reforestations.

Fig. 1. (A) General location of the study area in Northern Spain. (B) Specific locations of the radio-tracking study areas: 1, Zuia (Atlantic); 2, Kuartango (Mediterranean) (both in Alava province); 3, Baztán (Atlantic); 4, Ulzama (Atlantic); 5, Esteribar (Mediterranean) (in Navarra province); 6, study area during cold-spells.

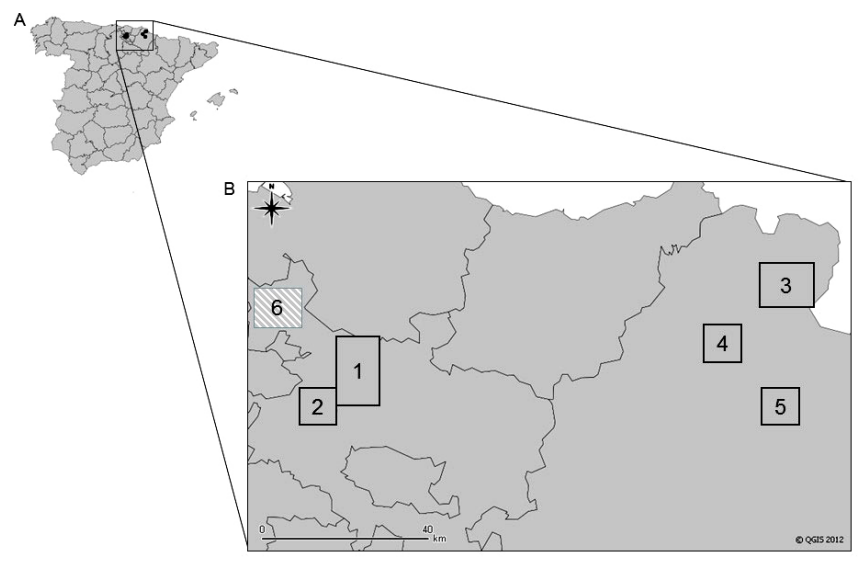

Study areas varied in the number of hunting days per week. Hunting was allowed seven days per week in Navarra. In Alava, number of hunting days allowed was usually four, but it varied among monitored areas, because part of monitored individuals in Zuia moved around the Natural Park of Gorbeia, where the number of hunting days per week was lower than in the rest of the areas (Fig. 1).

Weather varied among the three study winters: in 2009/2010 there were three cold spells in the radio-tracking study areas, one in December, one in January, and one in February. Cold spells were defined as periods when the average temperatures were in the lower 10 percentile for the area (in our case, below zero degrees), and when this situation remained more than four consecutive days (Yagüe et al. 2006), resulting in frost and snow covering the ground. In the other two winters no cold spells occurred.

\section{Radio-tracking data}

Each radio-tracking season lasted approximately four months, starting in December and ending with the prenuptial migration of all radio-tracked woodcock still alive at that time (late March to early April). We captured and marked individuals during the first half of December, to minimize the chance of capturing migrating birds (wintering populations increased regularly until late November, suggesting postnuptial migration until that time; Guzmán 2013). Captures were made at night in grasslands, dazzling the bird with a flashlight while another person captures it with a landing net (Duriez 2003). Captured birds were fitted with radios (TW-3 single celled tag by Biotrack) with a mass of $12 \mathrm{~g}(<4 \%$ of body mass). The transmitter was anchored by a simple loop forming a harness at the level of the keel and fixed with a special glue on the back of the bird (hypoallergenic livestock blue, Nasco, Fort Atkinson, USA), following the method described in Duriez (2003). The transmitter incorporated an activity sensor to detect if the individual was active or resting. If an individual remained in the same geographical position without activity between two consecutive diurnal or nocturnal locations, we approached to check if it was alive or dead. A total of 61 woodcock were trapped and aged based on plumage characteristics (Ferrand and Gossmann 2009). Four of these were never located after tagging, in four the transmitter was incorrectly fitted and fell off shortly after deployment, and two died of stress during the capture process. In the remaining 51 individuals (13 in 2008/2009; 17 in 2009/2010; 21 in 2010/2011), we could register either their death during the study winter (as corpses were found) or they were monitored at least until the end of February, when we were no longer able to locate them, suggesting that they had departed (prenuptial migration) and therefore survived the winter period. We identified predation as a cause of death when we found predation marks on the corpse or on a radio. In these cases, the possibility of scavenging following another source of death cannot be ruled out, for example if a hunter shot a woodcock but did not recover it, and then it was scavenged by a predator. Therefore, our predation estimates refer to "apparent predation." Birds were identified as dead through hunting if the radio was brought back to us by local hunters. In other cases, we classified the bird as "dead for unknown reasons."

Monitoring consisted of obtaining diurnal (10:00 to 15:00) and nocturnal (20:00 to 00:00) locations of all individuals until their death or onset of prenuptial migration. We approached woodcock by radio-triangulating locations up to $10-50 \mathrm{~m}$ from the bird during the day and 50-100 m during the night, first using a vehicle with a dipole antenna and then walking with a three-element Yagi antenna (Duriez 2003). When we located an individual, we assessed temperature with an outdoor digital thermometer. We aimed to monitor each individual at least twice a week during the day and the same frequency at night. When an individual was found dead, we estimated time of death as the midpoint between the last time alive and when it was found dead.

Commuting flight distance was calculated as the distance in meters between a diurnal location and a nocturnal location, i.e., the distance covered between the forest and the grasslands. The distance was calculated with a Geographic Information System (QGIS 1.8.0; QGIS Development Team 2013) using consecutive day-night locations, i.e., locations in a given day and of the same individual the subsequent night. The only exception was for two woodcocks for which we had too few consecutive day-night locations; here, we calculated the distance between a daytime location and the following available nighttime location, which was 2-3 days later. Results excluding these day-night time pairs were no different to those presented here. For analyses, we took into account only those individuals with three or more day-night location pairs ( $6 \pm 2$ pairs of locations for 34 individuals; mean $\pm \mathrm{SE}$ ).

During the first cold spell observed in the 2009/2010 winter, we were unable to locate several woodcocks that were regularly located using the ground-based telemetry protocol, but they returned to the study area subsequently. In the second and third cold spells that year, two light-aircraft flights were carried out 
after the movement of birds from the study area, to identify their location. The aircraft was equipped with two unidirectional antennas and we travelled across the study area, following the method described in Gilmer et al. (1981). We monitored the nearby area in a radius of $100 \mathrm{~km}$, with emphasis in the warmer and snow-free coastal areas (Fig. 1). When an individual was detected from the aircraft, we noted the approximate geographic location using GPS and the next day a more precise location was obtained from the ground following the protocol for commuting flights (see above). Escape flight distances were assessed as the distance between the last location (day or night) before the cold spell and the first location (day or night) during the cold spell. Because of the small sample size $(n=15)$, the escape flights were evaluated only descriptively.

\section{Statistical analyses}

We built Generalized Linear Mixed Models to assess factors associated with variations in commuting flight distance. The response variable was log-transformed to fit a normal distribution. Individual identity was included as a random intercept to account for repeated measures from individuals $(\mathrm{n}=$ 190 commuting flight distances from 34 individuals). As explanatory variables, we included temperature as a continuous variable, and climatic region (Atlantic or Mediterranean), age (adults or first-winter birds), and hunting opportunity (high, medium, or low) as factors. Hunting opportunity was categorized in relation to the number of hunting days per week in each area as "high" if hunting occurred seven days a week, "medium" if hunting occurred four days per week, or "low" when there were less than four hunting days per week. Temperature for this analysis was calculated as the average of the diurnal and nocturnal temperature records obtained for each individual in the day/night location considered for each commuting flight. We also included in the model the interaction between region and temperature.

For analyses of winter survival rate, we built Generalized Linear Mixed Models with the response variable "weekly survival" fitted to a binomial distribution (with a logit link), and following the basic assumptions of telemetry-based survival estimation (Murray 2006). This variable was scored as 1 if an individual had remained alive in a particular week, and 0 if it had died during that week. Individual identity was included as a random intercept to account for repeated measures of individuals $(n=551$ weekly registers from 51 individuals). As above, explanatory variables included temperature, climatic region, age, hunting opportunity, and the interaction between temperature and region. We did not consider commuting flight distance as an explanatory variable because sample size did not allow it: woodcock that died relatively early in the winter were not monitored sufficiently long to obtain enough night-day consecutive locations. For this analysis, temperature was calculated as the average minimum temperature of all days of a given week from the registers of the nearest climatic station to the study area (Pamplona climatic station in 2008/2009, and Vitoria climatic station in 2009/2010 and 2010/2011; https:// www.tutiempo.net/clima). The approximate distances to the climate stations from the field sites were: Pamplona-Esteribar, 15 km; Pamplona-Ulzama, $20 \mathrm{~km}$; Pamplona-Baztán, $30 \mathrm{~km}$; Vitoria-Zuia, $15 \mathrm{~km}$; Vitoria-Kuartango, $20 \mathrm{~km}$. We considered this to be a more reliable indication of the temperature experienced during that week than our records during the weekly location of the individuals, which were based on only one or two daytime and nighttime records. Furthermore, weather stations give a better picture of temporal variability in conditions that match the time scale we considered, whereas the ground-level measures are more appropriate to the scale and spatial nature of the commuting distance analysis. In both models, temperature was standardized prior to analyses (by subtracting the mean and dividing by the standard deviation) to help with model convergence.

We used an Information-Theoretic approach to select the best models explaining variation in commuting flight distance and survival rate, because this approach is widely used in the wildlife and ecological literature (Burnham and Anderson 2002). We used the AICc differences between models with different explanatory variables as criterion to select the best models, taking into account all possible combination of variables (Appendix 1). Models with less than $2 \triangle \mathrm{AICc}$ points in relation to the best model were considered to have the same empirical support (Burnham and Anderson 2002). We present the model-averaged coefficients of the explanatory variables included in those models, using this subset of models for their calculation (conditional average). Variables included in those models were not collinear (Cade 2015). We also calculated the relative variable importance, based on the sum of the weights of each of the models that included this variable (Burnham and Anderson 2002). Analyses were carried out with R 3.2.4 (R Core Team 2016), using the package MuMIn (Barton 2017). Means are presented \pm SE.

\section{RESULTS}

\section{Commuting flights}

Commuting flight distances ranged between $10.0 \mathrm{~m}$ and 5135.1 $\mathrm{m}$ (mean $961.5 \pm 1041.9 \mathrm{~m}, \mathrm{n}=190)$. The most important variables explaining variation in commuting flight distance were age group and temperature, variables that appeared in all the selected models (Tables 1 and 2). Commuting flights were shorter in first-winter birds than adults $(1380.48 \pm 1260.11 \mathrm{~m}$ for adults, $\mathrm{n}=94 ; 702.75$ $\pm 702.75 \mathrm{~m}$ for first-winter birds, $\mathrm{n}=75$ ), and were shorter under lower temperatures (Table 2).

Table 1. Results of models explaining woodcock (Scolopax rusticola) commuting flight distance. The table contains the full model and selected models (models with $\triangle \mathrm{AIC}$ less than 2 points from the best one). $\mathrm{K}=$ number of parameters. $\mathrm{W}=$ weight of the model.

\begin{tabular}{lcccc}
\hline \hline Models & K & AICc & $\Delta$ AICc & W \\
\hline Selected models & & & & \\
$\sim$ Temperature + Age + Hunting & 7 & 625.6 & 0 & 0.46 \\
$\sim$ Temperature + Age + Region & 6 & 626.7 & 1.1 & 0.27 \\
$\sim$ Temperature + Age + Hunting + Region & 8 & 626.8 & 1.1 & 0.27 \\
Full model & & & & \\
$\sim$ Temperature + Age + Hunting + Region + & 9 & 629.3 & 3.7 & - \\
Temperature*Region & & & & \\
\hline
\end{tabular}

The three best models also contained either hunting opportunity, region, or both as explanatory variables (Table 1). Flight distances appeared to be longer in Atlantic than Mediterranean regions, and under low more than medium and high hunting disturbance, 
although the parameter coefficients for some of the categories within those variables were unreliable (Table 2). The interaction between temperature and region did not appear in any of the best models.

Table 2. Model-averaged parameter coefficients of variables explaining woodcock (Scolopax rusticola) commuting flight distance from selected models. $\mathrm{CI}=95 \%$ confidence intervals, $\mathrm{RVI}=$ relative variable importance.

\begin{tabular}{lccccc}
\hline \hline Explanatory variables & Coefficient & SE & $\begin{array}{c}\text { CI } \\
(2.5 \%)\end{array}$ & $\begin{array}{c}\text { CI } \\
(97.5 \%)\end{array}$ & RVI \\
\hline Intercept & 7.41 & 0.40 & 6.60 & 8.14 & - \\
Age (first-winter birds) & -1.38 & 0.40 & -2.16 & -0.59 & 1 \\
Temperature & -0.98 & 0.53 & -0.39 & -0.07 & 1 \\
Hunting (medium) & -0.95 & 0.61 & -1.90 & -0.20 & 0.73 \\
Hunting (high) & -0.23 & 0.08 & -2.14 & 0.22 & 0.73 \\
Region (Mediterranean) & -0.52 & 0.60 & -1.60 & 0.03 & 0.54 \\
\hline
\end{tabular}

\section{Escape flights}

Of the 20 woodcock monitored in 2009/2010, only four did not make escape flights during cold spells. All others moved in at least one of the cold spells from the study area to other valleys (hereafter refuge areas; Fig. 1), characterized from being at lower elevation ( $200 \mathrm{~m}$ above sea level instead of $600 \mathrm{~m}$ on average for the study areas), and where ground was only partially covered with snow. The distance that woodcock moved during escape flights between the usual wintering areas and refuge areas was on average $23.4 \pm 6.0 \mathrm{~km}$ (Table 3 ). The birds remained in the refuge areas an average of eight days and went back to within $77 \mathrm{~m}$ of their previous wintering place (Table 3). Only one bird did not go back to its original wintering area, and remained during the rest of the winter in the refuge area.

Table 3. Parameters describing the displacements occurred during the three cold spells of 2009/2010. Figures in parentheses show sample size used in each case (although the occurrence or not of escape flights was monitored in all individuals, we were not able to identify the other parameters for all of these individuals).

\begin{tabular}{|c|c|c|c|c|}
\hline $\begin{array}{l}\text { Cold } \\
\text { spell }\end{array}$ & $\begin{array}{c}\text { Frequency of } \\
\text { escape flights } \\
(\%)^{\dagger}\end{array}$ & $\begin{array}{c}\text { Distance } \\
\text { covered } \\
(\mathrm{km})^{\ddagger}\end{array}$ & $\begin{array}{l}\text { Time in } \\
\text { refuge } \\
\text { (days) }\end{array}$ & $\begin{array}{l}\text { Fidelity of } \\
\text { return }(\mathrm{m})\end{array}$ \\
\hline December $^{\S}$ & $53.3(15)$ & $27.3 \pm 3.3(3)$ & - & - \\
\hline January & $64.3(14)$ & $22.2 \pm 6.6(4)$ & $8.2 \pm 2.2(8)$ & $76.1 \pm 4.4(3)$ \\
\hline February & $64.3(14)$ & $19.6 \pm 6.4(3)$ & $7.2 \pm 1.5(9)$ & $77.7 \pm 20.8(3)$ \\
\hline \multicolumn{5}{|c|}{$\begin{array}{l}{ }^{\dagger} \text { Proportion of monitored individuals in } 2009 / 2010 \text { that did escape } \\
\text { flights. } \\
{ }^{\ddagger} \text { Distance between the location before the cold spell and the first } \\
\text { location after displacement. } \\
{ }^{\S} \text { In the cold spell of December, it was impossible to describe the time } \\
\text { that they spent in the refuge or the fidelity when they came back to their } \\
\text { usual wintering places. }\end{array}$} \\
\hline
\end{tabular}

\section{Survival rate}

During the radio-tracking period, $54.9 \%$ of tagged woodcock $(60.7 \%$ of adults and $47.8 \%$ of first-winter birds) were monitored until the end of the winter season (Table 4), with the last location occurring between 21 February and 3 April. These birds were inferred to have undergone prenuptial migration and were therefore considered to have survived the winter. Among those that did not survive, $47.8 \%$ of individuals were hunted $(13.0 \%$ of adults and $34.8 \%$ of first-winter birds), $21.7 \%$ were killed by predators (17.4\% of adults and $4.3 \%$ of first-winter birds), and in $30.4 \%$ it was not possible to determine the cause of death $(17.4 \%$ and $13.0 \%$ of adults and first-winter birds; Table 4$)$. Woodcock that survived $(n=28)$ remained in the winter area an average of $105.9 \pm 11.6$ days from the beginning of December, $(109.0 \pm 11.6$ days for adults, $\mathrm{n}=19$; and 110.1 \pm 9.1 days for first-winter birds, $\mathrm{n}=11)$.

Table 4. Number of radio-tracked individuals in relation to fate in the different seasons and age groups.

\begin{tabular}{llcccc}
\hline \hline Winter & Age & Migrated & Hunted & Depredated & $\begin{array}{c}\text { Dead } \\
\text { (Unknown } \\
\text { reason) }\end{array}$ \\
\cline { 3 - 6 } & & & & & 3 \\
$2008 / 09$ & Adult & 1 & 1 & 1 & 1 \\
& First-winter & 2 & 4 & 0 & 0 \\
$2009 / 10$ & Adult & 11 & 1 & 2 & 2 \\
& First-winter & 1 & 0 & 0 & 1 \\
$2010 / 11$ & Adult & 5 & 1 & 1 & 0 \\
& First-winter & 8 & 4 & 1 & 7 \\
Total & & 28 & 11 & 5 &
\end{tabular}

The most important variable explaining variation in survival rate was hunting opportunity, appearing in all of the best models (Table 5). Winter survival rate was increasingly higher in areas with lower hunting opportunities (Table 6 and 7). Age, region, and temperature also appeared each in one of the three best models (Table 5): winter survival was higher in Mediterraneanthan Atlantic-climate region, in adults than in first-winter birds, and increased with increasing temperature (Table 6 and 7). However, the relative importance of these variables was much lower and parameter coefficients included zero when taking into account their confidence intervals (Table 6). The interaction between temperature and region did not appear in any of the best models.

Table 5. Results of models explaining winter woodcock (Scolopax rusticola) survival. The table contains the full model and selected models (models with $\triangle \mathrm{AIC}$ less than 2 points from the best one). $\mathrm{K}=$ number of parameters. $\mathrm{W}=$ weight of the model.

\begin{tabular}{lcccc}
\hline \hline Models & K & AICc & $\Delta$ AICc & W \\
\hline Selected models & & & & \\
$\sim$ Hunting & 4 & 187.8 & 0.0 & 0.41 \\
$\sim$ Hunting + Region & 5 & 188.6 & 0.9 & 0.26 \\
$\sim$ Hunting + Temperature & 5 & 189.6 & 1.8 & 0.16 \\
$\sim$ Hunting + Age & 5 & 189.6 & 1.8 & 0.16 \\
Full model & & & & \\
$\sim$ Hunting + Temperature + Age + Region + & 8 & 194.5 & 6.7 & - \\
Temperature*Region & & & & \\
\hline
\end{tabular}


Table 6. Model-averaged coefficients of the variables explaining winter woodcock (Scolopax rusticola) survival. CI $=95 \%$ confidence intervals, RVI = relative variable importance.

\begin{tabular}{lccccc}
\hline \hline Explanatory variables & Coefficient & SE & $\begin{array}{c}\text { CI } \\
(2.5 \%)\end{array}$ & $\begin{array}{c}\text { CI } \\
(97.5 \%)\end{array}$ & RVI \\
\hline $\begin{array}{l}\text { Intercept } \\
\begin{array}{l}\text { Hunting opportunity } \\
\text { (medium) }\end{array}\end{array}$ & -0.15 & 0.72 & 2.72 & 5.54 & - \\
$\begin{array}{l}\text { Hunting opportunity } \\
\text { (high) }\end{array}$ & -2.10 & 0.88 & -2.49 & 1.01 & 1 \\
$\begin{array}{l}\text { Region (Mediterranean) } \\
\text { Temperature }\end{array}$ & 0.75 & -3.82 & -0.42 & 1 \\
Age (first-winter birds) & -0.11 & 0.23 & -0.63 & 2.14 & 0.26 \\
\hline
\end{tabular}

Table 7. Winter survival probabilities $\left(\right.$ Swinter $=\mathrm{Sweek}^{\wedge}$ Nweeks, Powell 2007) in relation to hunting opportunity, region, and age group. Weekly survival rates estimated from model averaged coefficients in Table 6. We estimated the length of winter as 16 weeks (from December to March).

\begin{tabular}{lccccccc}
\hline \hline & \multicolumn{3}{c}{ Atlantic } & & \multicolumn{3}{c}{ Mediterranean } \\
\cline { 2 - 4 } $\begin{array}{l}\text { Hunting } \\
\text { opportunity }\end{array}$ & Low & Medium & High & & Low & Medium & High \\
\hline Adults & & & & & & & \\
First-winter birds & 0.73 & 0.52 & 0.09 & & 0.86 & 0.74 & 0.30 \\
\hline
\end{tabular}

\section{DISCUSSION}

Our data support the hypothesis that commuting flight distances are influenced by temperature, and that winter survival rate was influenced by hunting. On the other hand, we did not find support for the hypothesis that the relationship between temperature and either mobility or survival rate was influenced by climatic region (although results suggested that survival was higher in Mediterranean than Atlantic regions).

\section{Commuting and escape flights}

Our results showed that age and temperature were important factors related to the length of commuting flights for woodcock wintering in Spain. In relation to age, we found that adults moved on average longer distances than first-winter birds. Similar results were found for woodcock in Ireland (Wilson 1982) and for other migratory birds, which has been interpreted as an indication that the location of the most appropriate (even if further) foraging areas is learned through experience (Riotte-Lambert and Weimerskirch 2013). Additionally, adult birds may store more fat than first-winter birds (Duriez et al. 2004b), which may result in them being better able to meet the increased demands from performing longer flights for food. Our results thus support that first-winter birds may be less efficient at finding good foraging areas and less proficient at optimizing the time spent feeding (Duriez et al. 2004a).

A study on American Woodcock showed that woodcock moved increasingly further distances with higher temperatures (Doherty et al. 2010), which was interpreted as meaning that the cost of travelling to better foraging places is compensated by lower thermoregulatory costs under higher temperatures. In our case, we found a negative correlation between temperature and commuting flight distance. According to Duriez et al. (2004a), who found similar results for Eurasian Woodcock in France, this pattern could be the result of a compensatory mechanism in response to higher energy needs for thermoregulation in cold temperatures. Braña et al. (2010) found in Atlantic Spain a positive correlation between temperature and the time initiating commuting flights after sunset, with flights starting earlier in colder weather. Overall, these results suggest that when temperature falls, increasing energy expenditure by thermoregulation, woodcock invest more in foraging flights, with higher activity and greater displacements, probably in an attempt to optimize feeding (Charnov 1976). The extreme case would be represented by the responses to cold spells, when movement distances were an order of magnitude higher than usual. In France, responses to cold spells of different intensity have been studied, and a threshold in relation to the magnitude of the cold spell has been found. Thus, when the cold spell is not very intense, few individuals change their usual behavior and displacements are shorter, whereas when it exceeds a certain level, a higher number of individuals show escape behaviors and the magnitude of the displacements is higher as well (Péron et al. 2011a). This seems consistent with the results of the present paper, in which the largest displacements occurred in the winter 2009/2010 under particularly harsh weather conditions, and did not influence equally all individuals: although some individuals moved to refuge areas, others faced the harsh conditions in their usual wintering places. Therefore, this compensatory mechanism appears to act at different levels in a gradient from low to high intensity, from daily travels to feed in the grasslands near the forest (commuting flights), to the great journeys to more temperate zones (escape flights), conditioning woodcock's winter mobility at different temporal and spatial scales.

In contrast to our hypothesis, we did not find differences among regions in commuting flight distances in relation to temperature. This may indicate that our initial hypothesis (that in Mediterranean-climate region, higher shrub vegetation cover modifies thermoregulation costs for woodcock or worm accessibility under low air temperatures) is not supported. In fact, habitat utilization by predators can reflect availability of resources (Davoren et al. 2003), so our results may indicate that both climatic regions in fact have similar food resources, e.g., number and distance of grasslands where to feed on earthworms. Further studies should evaluate whether abundance and distribution of grasslands and forest patches is an important factor for winter ecology of woodcock, and if there are differences in food resources, spatial distribution of forest and grassland areas, or soil temperature according to climate regions.

\section{Winter survival rate}

The most frequently identified cause of death of our tracked woodcock was hunting, affecting mainly first-winter birds. Number of woodcock killed by predation were only half in relation to hunted birds. This difference may even be underestimated, because the four woodcock that were never located after tagging disappeared in areas with high hunting opportunity, so it is possible that they were hunted by hunters 
who did not return the transmitter, but this was impossible to evaluate.

Furthermore, our study showed that survival rate was lower in areas with higher hunting opportunity. Survival rate was markedly low when it was possible to hunt all days of the week (from 0.13 to 0.20 depending of region and age group). It is important to underline that because of our work design, the variable hunting opportunity was somewhat collinear with winter because the category "high" in hunting opportunity only occurred in one of the study winters. Therefore, it is not possible to determine if part of the variance was explained by differences among study years in relation to factors unmonitored in the study. However, differences in survival rates between all categories of hunting opportunity followed a gradual pattern, and survival rate was also $11-28 \%$ lower in areas with medium than low hunting opportunities (calculated from Table 7), which were sampled in two different winters, so hunting opportunity appears to have an effect on survival independently of interannual differences.

More hunting opportunities, i.e., a higher number of days when hunting is allowed, do not necessarily indicate higher hunting pressure, and even the number of hunting days may be reactively reduced in areas where the hunting pressure is too high. However, there are some clues that indicate that, in our case, the positive relationship between this parameter and hunting pressure is likely. In Guipuzkoa (a province in Northern Spain close to our study sites), woodcock hunting is also allowed every day of the week. In that area, there exists an administrative mechanism whereby hunters have to inform the authorities about their daily hunting activity (including hunting bags). Results from that area show how hunting actually occurs with high intensity (in terms of number of hunting sessions) each weekday, and that spatially there exists a positive correlation between the total hunting sessions per area and total woodcock hunted $(n=11$ areas, $r=$ 0.96; based on information in García and Romero 2015, unpublished data). This suggests that increasing the number of days when hunting is possible probably increases the total number of hunting sessions in an area, and thus hunting pressure.

Our results coincide with other woodcock studies that indicate that hunting mortality is an important factor explaining survival rate. These studies also suggest that hunting is an additive mortality factor, because annual survival rates for woodcock wintering in areas without hunting (Duriez et al. 2005b, Aradis et al. 2008) was higher than annual survival rate for woodcock in areas with hunting activity (Hoodless and Coulson 1994, Tavecchia et al. 2002, Bauthian et al. 2006; see also Bruggink et al. 2013 for American Woodcock). According to that, and given that woodcock winter survival rates in this study varied in relation to hunting opportunity, this may indicate source-sink population dynamics among areas with different hunting pressure, as described in France (Péron et al. $2011 b$ and 2012).

The winter survival rate found in our study $(0.55, \mathrm{n}=51)$ was lower than that reported for France for both adults and firstwinter birds ( 0.77 and 0.59 , respectively; Tavecchia et al. 2002), and also lower than the annual survival rate reported for adults in the UK (0.58; Hoodless and Coulson 1994). It was only higher than that reported for first-winter birds in the UK $(0.47$; Hoodless and Coulson 1994). This is a first estimate, and may be influenced by our limited sample size. However, this may also suggest that winter mortality of woodcock wintering in Spain may be high in relation to other areas, at least in certain conditions. Indeed, winter survival estimated for the areas with high hunting opportunities, if confirmed in further studies, could reflect that populations there are unsustainable without annual recruitment of first-winter birds (Perón et al. 2011b). Right now, populations seem stable (BirdLife International 2016), but it appears strongly necessary to continue monitoring both hunting pressure and survival rates to identify which places could act as a sink and to be able to adjust management if necessary to allow population sustainability (Péron et al. 2011b, 2012).

Our results also suggest that survival is higher in Mediterranean rather than Atlantic climate region, supporting the hypothesis that in Mediterranean regions, thermoregulation costs would be lower or worm availability be higher, and therefore that these regions could be important for woodcock. However, the confidence interval for the effect size of this variable included zero, so these results should be confirmed. It may be particularly useful if future studies on winter survival of woodcock in Spain consider this variable.

In contrast to our hypothesis, we did not find a marked effect of temperature on winter survival rate, in either of the two climatic regions. With low temperatures, nonhibernating endotherms are confronted with increasing energy requirements to enhance thermogenesis while food is a scarce resource (Boos et al. 2007, Deville et al. 2014). In many bird species it has thus been shown that winter conditions such as low temperatures or consecutive frosts influence survival (e.g., Deville et al. 2014, Johnston et al. 2016). In France, a negative relationship between winter temperature and woodcock survival was also found, as well as escape behavior below a certain temperature threshold (Tavecchia et al. 2002, Péron et al. 2011a), presumably because dealing with such conditions would be riskier than moving away from their usual wintering areas (Duriez 2003). The fact that we did not find a significant relationship between temperature and survival rate, may reflect that the measure of temperature used for this analyses was not sufficiently precise because of the distance between the climatic stations and the areas used by woodcock. However, and alternatively, it may also be a consequence of the closeness of suitable refuge areas found in our study, which may provide an escape for woodcock to compensate the negative effects of low temperatures. Most woodcock showed escape flights during the cold spells, and although the refuge areas were used only for limited amounts of time, they could be very important for the birds during harsh conditions. This underlines the importance of developing future studies to understand how they are used, and whether or not woodcock density or harvest pressure is greater there during cold spells.

Responses to this article can be read online at: http://www.ace-eco.org/issues/responses.php/1096

\section{Acknowledgments:}

This work was partially funded by the Committee of Hunting and Continental Fishing, under the Research Project: 200430E471. We are grateful to all hunters who participated in the capturing and 
marking of individuals, especially Ibon Telletxea and Rubén Ibanez, and two anonymous referees for constructive and useful comments that improved the manuscript. Iñigo Mendiola gave us useful information about hunting in Guipuzkoa province.

\section{LITERATURE CITED}

Aebischer, N. J., and D. Baines. 2008. Monitoring gamebird abundance and productivity in the UK: the GWCT long-term datasets. Revista Catalana d'Ornitologia 24:30-43.

Aradis, A., M. W. Miller, G. Landucci, P. Ruda, S. Taddei, and F. Spina. 2008. Winter survival of Eurasian Woodcock Scolopax rusticola in central Italy. Wildlife Biology 14:36-43. http://dx.doi. org/10.2981/0909-6396(2008)14[36:WSOEWS]2.0.CO;2

Austin, D., W. D. Bowen, J. I. McMillan, and S. J. Iverson. 2006. Linking movement, diving, and habitat to foraging success in a large marine predator. Ecology 87:3095-3108. http://dx.doi. org/10.1890/0012-9658(2006)87[3095:LMDAHT]2.0.CO;2

Bakken, G. S. 1990. Estimating the effect of wind on avian metabolic rate with standar operative temperature. Auk 107:587-594.

Barton, K. 2017. MuMIn: multi-model inference. $R$ package version 1.40.0. $\mathrm{R}$ Foundation for Statistical Computing, Vienna, Austria. [online] URL: https://cran.r-project.org/web/packages/ MuMIn/

Bauthian, I., F. Gossmann, Y. Ferrand, and R. Julliard. 2007. Quantifying the origin of woodcock wintering in France. Journal of Wildlife Management 71(3):701-705. http://dx.doi. org/10.2193/2004-354

Bauthian, I., I. Illjinsky, S. Fokin, R. Julliard, F. Gossmann, and Y. Ferrand. 2006. Survival rates of Russian woodcocks. International Wader Studies 13:62-65.

BirdLife International. 2016. Scolopax rusticola. The IUCN Red List of Threatened Species, Cambridge, UK. [online] URL: http:// dx.doi.org/10.2305/IUCN.UK.2016-3.RLTS.T22693052A86627978. en

Boos, M., T. Zorn, G. Delacour, and J. P. Robin. 2007. Weather and body condition in wintering mallards Anas platyrhynchos. Bird Study 54:154-159. http://dx.doi.org/10.1080/00063650709461470

Braña, F., L. Prieto, and P. González-Quirós. 2010. Habitat change and timing of dusk flight in the Eurasian Woodcock: a trade-off between feeding and predator avoidance? Annales Zoologici Fennici 47:206-214. http://dx.doi.org/10.5735/086.047.0305

Brochet, A.-L., M. Guillemain, C. Lebarbenchon, G. Simon, H. Fritz, A. J. Green, F. Renaud, F. Thomas, and M. Gauthier-Clerc. 2009. The potential distance of highly pathogenic avian influenza virus dispersal by Mallard, Common Teal and Eurasian Pochard. EcoHealth 6:449-457. http://dx.doi.org/10.1007/s10393-010-0275-4

Bruggink, J. G., E. J. Oppelt, K. E. Doherty, D. E. Andersen, J. Meunier, and R. S. Lutz. 2013. Fall survival of American woodcock in the western Great Lakes Region. Journal of Wildlife Management 77(5) 1021-1030. http://dx.doi.org/10.1002/jwmg.547

Burger, J., and M. Gochfeld. 2004. Marine birds as sentinels of environmental pollution. EcoHealth 1:263-274. http://dx.doi. org/10.1007/s10393-004-0096-4
Burnham, K. P., and D. R. Anderson. 2002. Model selection and multimodel inference: a practical information-theoretic approach. Second edition. Springer-Verlag, New York, New York, USA. http://dx.doi.org/10.1007/b97636

Cade, B. S. 2015. Model averaging and muddled multimodel inferences. Ecology 96(9):2370-2382. http://dx.doi.org/10.1890/14-1639.1

Charnov, E. L. 1976. Optimal foraging, the marginal value theorem. Theoretical Population Biology 9(2):129-136. http://dx. doi.org/10.1016/0040-5809(76)90040-X

Cramp, S., and K. E. L. Simmons. 1983. Handbook of the Birds of Europe, the Middle East and North Africa, III Waders to Gulls. Oxford University Press, Oxford, UK.

Davoren, G. K., W. A. Montevecchi, and J. T. Anderson. 2003. Distributional patterns of a marine bird and its prey: habitat selection based on prey and conspecific behaviour. Marine Ecology Progress Series 256:229-242. http://dx.doi.org/10.3354/ meps 256229

Deville, A.-S., S. Labaude, J.-P. Robin, A. Béchet, M. GauthierClerc, W. Porter, M. Fitzpatrick, P. Mathewson, and D. Grémillet. 2014. Impacts of extreme climatic events on the energetics of longlived vertebrates: the case of the Greater Flamingo facing cold spells in the Camargue. Journal of Experimental Biology 217:3700-3707. http://dx.doi.org/10.1242/jeb.106344

Doherty, K. E., D. E. Andersen, J. Meunier, E. Oppelt, R. S. Lutz, and J. G. Bruggink. 2010. Foraging location quality as a predictor of fidelity to a diurnal site for adult female American Woodcock Scolopax minor. Wildlife Biology 16:379-388. http://dx.doi. org/10.2981/09-100

Duriez, O. 2003. Individual wintering strategies in the Eurasian Woodcock Scolopax rusticola: energetic trade-offs for habitat selection. Dissertation,.Université de Paris VI, Paris, France.

Duriez, O., C. Eraud, C. Barbraud, and Y. Ferrand. 2005b. Factors affecting population dynamics of Eurasian Woodcocks wintering in France: assessing the efficiency of a hunting-free reserve. Biological Conservation 122:89-97. http://dx.doi.org/10.1016/j. biocon.2004.07.002

Duriez, O., Y. Ferrand, F. Binet, E. Corda, F. Gossmann, and H. Fritz. 2005a. Habitat selection of the Eurasian Woodcock in winter in relation to earthworms availability. Biological Conservation 122(3):479-490. http://dx.doi.org/10.1016/j.

biocon.2004.08.011

Duriez, O., H. Fritz, F. Binet, Y. Tremblay, and Y. Ferrand. 2004a. Individual activity in wintering Eurasian Woodcocks: starvation versus predation risk trade-off? Animal Behaviour 69:39-49. http://dx.doi.org/10.1016/j.anbehav.2004.04.009

Duriez, O., L. Pastout Lucchini, M. Boos, O. Chastel, H. Fritz, Y. Ferrand, and J. Clobert. 2004b. Low levels of energy expenditure in a nocturnal, forest-dwelling wader, the Eurasian Woodcock Scolopax rusticola. Ardea 92:31-42.

Fauchald, P., and T. Tveraa. 2006. Hierarchical patch dynamics and animal movement pattern. Oecologia 149:383-395. http://dx. doi.org/10.1007/s00442-006-0463-7

Ferrand, Y., and F. Gossmann. 2009. La bécasse des bois. Histoire naturelle. Effet de lisière-éditeur, Saint-Lucien, France. 
Ferrand, Y., F. Gossmann, C. Bastat, and M. Guénézan. 2008. Monitoring of the wintering and breeding Woodcock populations in France. Revista Catalana d'Ornitologia 24:44-52.

Gill, J. A. 2007. Approaches to measuring the effects of human disturbance on birds. Ibis 149(Suppl1):9-14. http://dx.doi. org/10.1111/j.1474-919X.2007.00642.x

Gilmer, D. S., L. M. Cowardin, R. L. Duval, L. M. Mechlin, and C. W. Shaiffer. 1981. Procedures for the use of aircraft in wildlife biotelemetry studies. U.S. Fish and Wildlife Service Resource Publication, Washington, D.C., USA.

Gossmann, F., and Y. Ferrand. 2000. Impact of the 1996-97 cold spell on Woodcock in France based on ring recoveries. Pages 37-39 in H. Kalchreuter, editor. Fifth European Woodcock and Snipe Workshop: Proceedings of an International Symposium of the Wetlands International Woodcock and Snipe Specialist Group, Czempin, Poland. Wetlands International, Wageningen, The Netherlands.

Gourlay-Larour, M.-L., V. Schricke, C. Sorin, M. L'Hostis, and A. Caizergues. 2012. Movements of wintering diving ducks: new insights from nasal saddled individuals. Bird Study 59:266-278. http://dx.doi.org/10.1080/00063657.2012.697867

Guzmán, J. L. 2013. Factores que modulan la abundancia poblacional de la becada (Scolopax rusticola): implicaciones para su gestión y conservación. Dissertation. Universidad de Castilla La Mancha, Spain.

Guzmán, J. L., and B. Arroyo. 2015. Predicting winter abundance of woodcock Scolopax rusticola using weather data: implications for hunting management. European Journal of Wildlife Research 61:467-474. http://dx.doi.org/10.1007/s10344-015-0918-4

Heward, C. J., A. N. Hoodless, G. J. Conway, N. J. Aebischer, S. Gillings, and R. J. Fuller. 2015. Current status and recent trend of the Eurasian Woodcock Scolopax rusticola as a breeding bird in Britain. Bird Study 62:535-551. http://dx.doi.org/10.1080/00063657.2015.1092497

Hoodless, A. N., and J. C. Coulson. 1994. Survival rates and movements of British and continental Woodcock Scolopax rusticola in the British Isles. Bird Study 41:48-60. http://dx.doi. org/10.1080/00063659409477197

Johnston, A., R. A. Robinson, G. Gargallo, R. Julliard, H. Van Der Jeugd, and S. R. Baillie. 2016. Survival of Afro-Palaearctic passerine migrants in western Europe and the impacts of seasonal weather variables. Ibis 158:465-480. http://dx.doi.org/10.1111/ ibi. 12366

Lavelle, P. 1988. Earthworm activities and the soil system. Biology and Fertility of Soils 6:237-251. http://dx.doi.org/10.1007/ BF00260820

Masse, R. J., B. C. Tefft, J. A. Amador, and S. R. McWilliams. 2013. Why woodcock commute: testing the foraging-benefit and predation-risk hypotheses. Behavioral Ecology 24(6):1348-1355. http://dx.doi.org/10.1093/beheco/art073

Murray, D. L. 2006. On improving telemetry-based survival estimation. Journal of Wildlife Management 70(6):1530-1543. http://dx.doi.org/10.2193/0022-541X(2006)70[1530:OITSE]2.0.CO;2
Péron, G. 2013. Compensation and additivity of anthropogenic mortality: life-history effects and review of methods. Journal of Animal Ecology 82:408-417. http://dx.doi.org/10.1111/1365-2656.12014

Péron, G., Y. Ferrand, R. Choquet, R. Pradel, F. Gossmann, C. Bastat, M. Guénézan, I. Bauthian, R. Julliard, and O. Gimenez. 2012. Spatial heterogeneity in mortality and its impact on the population dynamics of Eurasian Woodcocks. Population Ecology 54: 305-312. http://dx.doi.org/10.1007/s10144-012-0309-6

Péron, G., Y. Ferrand, F. Gossmann, C. Bastat, M. Guénézan, and O. Gimenez. 2011a. Escape migration decisions in Eurasian Woodcocks: insights from survival analyses using large-scale recovery data. Behavioral Ecology and Sociobiology 65:1949-1955. http://dx.doi.org/10.1007/s00265-011-1204-4

Péron, G., Y. Ferrand, F. Gossmann, C. Bastat, M. Guenezan, and O. Gimenez. 2011b. Nonparametric spatial regression of survival probability: visualization of population sinks in Eurasian Woodcock. Ecology 92:1672-1679. http://dx.doi.org/10.1890/10-2224.1

Powell, L. A. 2007. Approximating variance of demographic parameters using the delta method: a reference for avian biologists. Condor 109(4):949-954. http://dx.doi.org/10.1650/0010-5422 (2007)109[949:AVODPU]2.0.CO;2

QGIS Development Team. 2013. QGIS Geographic Information System. Open Source Geospatial Foundation Project. [online] URL: http://qgis.osgeo.org

R Core Team. 2016. R: A language and environment for statistical computing. R Foundation for Statistical Computing, Vienna, Austria. [online] URL: https://www.R-project.org/

Riotte-Lambert, L., and H. Weimerskirch. 2013. Do naive juvenile seabirds forage differently from adults? Proceedings of the Royal Society B-Biological Sciences 280:20131434. http://dx. doi.org/10.1098/rspb.2013.1434

Rodríguez-Teijeiro, J. D., F. Sardà-Palomera, and M. Puigcerver. 2012. Post-breeding movements and migration patterns of western populations of Common Quail (Coturnix coturnix): from knowledge to hunting management. Animal Biodiversity and Conservation 35:333-342.

Sauter, A., F. Korner-Nievergelt, and L. Jenni. 2010. Evidence of climate change effects on within-winter movements of European Mallards Anas platyrhynchos. Ibis 152:600-609. http://dx.doi. org/10.1111/j.1474-919X.2010.01028.x

Specht, R. L. 1969. A comparison of the sclerophyllous vegetation characteristic of Mediterranean type climates in France, California, and southern Australia. I. Structure, morphology, and succession. Australian Journal of Botany 17(2):277-292. http://dx. doi.org/10.1071/BT9690277

Stephens, S. E., D. N. Koons, J. J. Rotella, and D. W. Willey. 2004. Effects of habitat fragmentation on avian nesting success: a review of the evidence at multiple spatial scales. Biological Conservation 115:101-110. http://dx.doi.org/10.1016/S0006-3207(03)00098-3

Tavecchia, G., R. Pradel, F. Gossmann, C. Bastat, Y. Ferrand, and J. D. Lebreton. 2002. Temporal variation in annual survival probability of the Eurasian Woodcock Scolopax rusticola wintering in France. Wildlife Biology 8:21-30. 
Wiersma, P., and T. Piersma. 1994. Effects of microhabitat, flocking, climate and migratory goal on energy expenditure in the annual cycle of red knots. Condor 96:257-279. http://dx.doi. org/10.2307/1369313

Wikelski, M., E. M. Tarlow, A. Raim, R. H. Diehl, R. P. Larkin, and G. H. Visser. 2003. Avian metabolism: costs of migration in free-flying songbirds. Nature 423(6941):704-704. http://dx.doi. org/10.1038/423704a

Williams, C. K., R. S. Lutz, R. D. Applegate, and W. Palmer. 2004. Winter survival and additive harvest in Northern Bobwhite coveys in Kansas. Journal of Wildlife Management 68(1):94-100. http:// dx.doi.org/10.2193/0022-541X(2004)068[0094:WSAAHI]2.0.CO;2

Wilson, H. J. 1982. Movements, home ranges, and habitat use of wintering woodcocks in Ireland. U.S. Fish and Wildlife Service Wildlife Research Report 14:168-178.

Yagüe, C., M. Martija, J. Torres, A. Maldonado, and E. Zurita. 2006. Análisis estadístico de las olas de calor y frío en España. XXIX Jornadas Científicas de la AME 20-26. [online] URL: http:// pendientedemigracion.ucm.es/info/Geofis/g-micromet_varclima/ articulos/Yague_et_alAME2006.pdf 
Appendix 1. AIC of all possible models resulting from the combinations of the variables included in the model selection procedure.

\begin{tabular}{|c|c|c|c|c|}
\hline Models & $\mathrm{K}$ & AICc & $\triangle \mathrm{AICc}$ & W \\
\hline$\sim$ Hunting & 4 & 187.8 & 0.0 & 0.26 \\
\hline$\sim$ Hunting + Region & 5 & 188.6 & 0.9 & 0.17 \\
\hline Hunting + Temperature & 5 & 189.6 & 1.8 & 0.11 \\
\hline$\sim$ Hunting + Age & 5 & 189.6 & 1.8 & 0.11 \\
\hline$\sim$ Hunting + Region + Temperature & 6 & 190.5 & 2.7 & 0.07 \\
\hline$\sim$ Hunting + Age + Region & 6 & 190.7 & 2.9 & 0.06 \\
\hline$\sim$ Hunting + Age + Temperature & 6 & 191.4 & 3.7 & 0.04 \\
\hline$\sim$ Null model & 2 & 191.7 & 3.9 & 0.04 \\
\hline$\sim$ Hunting + Region + Temperature + Region $*$ Temperature & 7 & 192.4 & 4.7 & 0.03 \\
\hline$\sim$ Hunting + Age + Region + Temperature & 7 & 192.5 & 4.7 & 0.03 \\
\hline$\sim$ Region & 3 & 192.9 & 5.1 & 0.02 \\
\hline$\sim$ Temperature & 3 & 193 & 5.2 & 0.02 \\
\hline$\sim$ Age & 3 & 193.4 & 5.6 & 0.02 \\
\hline$\sim$ Region + Temperature & 4 & 194.3 & 6.5 & 0.01 \\
\hline$\sim$ Hunting + Age + Region + Temperature+Region * Temperature & 8 & 194.5 & 6.7 & 0.01 \\
\hline$\sim$ Age + Temperature & 4 & 194.8 & 7.0 & 0.01 \\
\hline$\sim$ Age + Region & 4 & 194.8 & 7.1 & 0.01 \\
\hline$\sim$ Region + Temperature + Region * Temperature & 5 & 196.2 & 8.5 & 0.00 \\
\hline$\sim$ Age + Region + Temperature & 5 & 196.2 & 8.5 & 0.00 \\
\hline$\sim$ Age + Region + Temperature + Region * Temperature & 6 & 198.2 & 10.4 & 0.00 \\
\hline
\end{tabular}

